\title{
Improving online video lectures: learning challenges created by media
}

\author{
Christopher Lange ${ }^{1}$ and Jamie Costley ${ }^{2^{*}}$
}

\author{
* Correspondence: costleyjamie@ \\ gmail.com \\ ${ }^{2}$ Educational Research Lab, Prince \\ Sultan University, Prince Nasser Bin \\ Farhan St, Riyadh 12435, Saudi \\ Arabia \\ Full list of author information is \\ available at the end of the article
}

\begin{abstract}
The use of media within online university courses has been shown to aid the learning process with the delivery of information through various formats. However, issues that inhibit learning have been found when media are used inappropriately. Based on an examination of extant media research, this study arranges common media delivery problems into five main categories: pace, intelligibility, quality, media diversity, and congruence. Students taking online courses were asked to comment on the media used in their classes. Each of their comments was paired with one of the five categories with justification provided for the categorizations. Through analysis of these learner comments, this study examines the extent to which media delivery problems occur among a specific sample of online university learners in South Korea. The underlying pedagogy that explains the issues caused by inadequate delivery of media is also discussed, followed by recommended solutions that can address such pedagogical concerns. The results not only highlight existing solutions to these types of media problems but also build on them by suggesting other techniques in which media can be delivered so that the overall online learning experience may be enhanced.

Keywords: Audio, Cognitive load, E-learning, Media, Video lecture, Visual
\end{abstract}

\section{Springer Open}

\section{Introduction}

E-learning is defined as the use of computer aided instruction delivered online to promote learning from multiple electronic sources (Mayer, 2014). Due to its ubiquitous nature in addition to technological advances that allow for the dissemination of information to large groups of learners, e-learning is ideal for university students in South Korea and around the world. This is evident in the gradual increase of university students participating in massive online university courses (Kim, Kwon, \& Cho, 2011). Within massive e-learning courses, video lecture viewing is the primary activity among learners (Sinha, Jermann, Li, \& Dillenbourg, 2014). Video lectures provide various learner/system interactional features designed to supplement content delivered through various forms of both auditory and visual media (Alraimi, Zo, \& Ciganek, 2015; Breslow et al., 2013). The way in which media is used is possibly the most salient aspect of video lectures because through it, most forms of instruction and learner interaction are possible and e-learning cannot exist without it. It contributes to the

(c) The Author(s). 2020 Open Access This article is licensed under a Creative Commons Attribution 4.0 International License, which permits use, sharing, adaptation, distribution and reproduction in any medium or format, as long as you give appropriate credit to the original author(s) and the source, provide a link to the Creative Commons licence, and indicate if changes were made. The images or other third party material in this article are included in the article's Creative Commons licence, unless indicated otherwise in a credit line to the material. If material is not included in the article's Creative Commons licence and your intended use is not permitted by statutory regulation or exceeds the permitted use, you will need to obtain permission directly from the copyright holder. To view a copy of this licence, visit http://creativecommons.org/licenses/by/4.0/. 
way lectures are perceived by the students, and ultimately influences how they cognitively process information delivered to them (Mayer, 2014).

The application of media within video lectures allows learners to process information received through both visual and auditory channels. Such processing occurs by organizing the information in working memory and transferring it to long term memory. This should ideally lead to greater schema construction, and ultimately a clearer understanding of the content (Mayer, 2014). Various forms of visual media designed to enhance student attention and engagement with video lectures include illustrations, images, graphs, maps, animations, videos, slides, and text (Kizilcec, Bailenson, \& Gomez, 2015; Mayer, 2014; Schmidt-Weigand \& Scheiter, 2011). Efficient delivery of visual media allows students to reason and make inferences by visualizing how certain processes occur (Rasch \& Schnotz, 2009). Auditory media are designed to promote student engagement through formats such as music, sound effects, spoken text, instructor's voice, and narration (Kizilcec et al., 2015; Mayer, 2014). Effective delivery of auditory media provides verbal information of which learners can efficiently process, adds emphasis to such information, and attracts learners' attention through nonverbal sounds and music (Costley \& Lange, 2017a; Mayer, 2014). Although there are clear benefits to using both visual and auditory media in video lectures, online instructors need to be mindful of potential issues with inefficient media delivery. Specifically, problems with information transfer can occur if media are delivered in ways that limit their concentration, attention, interest, and engagement (Curry, Bernard, \& Kolek, n.d.; Koumi, 2013), and overload working memory (Cierniak, Scheiter, \& Gerjets, 2009; Mayer, 2014; Rasch \& Schnotz, 2009).

\section{Current study}

The first step of this study was to examine extant online learning media research in order to get an overview of the general types of media delivery problems that may negatively affect learning. The research was examined, and common media issues that were revealed in the existing research were noted. After identifying these common media issues expressed by various researchers within the field, we decided to categorize them based on how they were described in the research that we examined. A total of five media categories were generated: pace (the rate of speed at which audio and visuals are delivered), intelligibility (the level at which students can accurately see or hear aspects of the video lecture), quality (media presentation and design), media diversity (the use of various forms of media), and congruence (two or more types of media used simultaneously). Based on extensive examination of existing research, detailed explanations of various types of media delivery issues occurring within these categories can be found in the "Literature review" section that follows.

While there is an abundance of existing research that focus on media delivery problems, evidence regarding how students perceive and understand these problems is scant. In order to more deeply understand how these problems occur within our sample of university students enrolled in massive online courses in South Korea, the current study examines student complaints and how they fit within common media delivery issues found in the examination of current research. Furthermore, much research into the use of media in online contexts focuses on quantitative outcomes based on 
large scale surveys or experiments. While this is a valuable avenue of research, the present student seeks to look at student perceptions of media from a different lense. The goal of this study is to reveal the common issues perceived by the participants in our study, to discuss the underlying pedagogy that provides an explanation as to why such media delivery negatively affects learning, to examine instructional intervention recommendations to address these issues, and to provide new recommendations to address existing pedagogical concerns. Based on these research goals, this study will address the following research questions:

\section{Research questions}

Q1.To what extent do participants of this study experience negative media delivery issues found in existing e-learning research?

Q2.What is the underlying pedagogy that explains the negative effects on learning caused by inadequate media delivery identified in this study?

Q3.What solutions can be applied to address current pedagogical concerns involving ineffective media delivery?

\section{Literature review}

\section{Media and learning}

Instructional media in e-learning can be viewed as a way in which information is delivered to learners through various electronic sources (Mayer, 2014). From a learning perspective, media can have a profound impact on how learners process and ultimately comprehend the content due to its essential role as content deliverer. Ineffective use of media contributes to interest, engagement, and motivation issues, and ultimately contributes to a lack of understanding in e-learning environments (Costley \& Lange, 2017a; Mayer, 2014). This negative effect on learning occurs due to either a loss of focus on the content or problems associated with attempting to process the content (Mayer, 2014; Molnar, 2017). Various media factors including pace, intelligibility, quality, diversity, and congruence can contribute to these learning problems if used ineffectively. Therefore, in order to promote learning within online courses, ways in which media factors contribute to engagement and processing issues and ways in which such issues can be alleviated should be examined.

\section{Media factors}

Pace

Pace refers to the rate of speed at which information is presented through visual media, which can affect the way in which learners engage in the content and process information (Fisher, Howardson, Wasserman, \& Orvis, 2017). If visual media are delivered too quickly, student comprehension levels may suffer (Fisher et al., 2017). Although there appears to be a tipping point for when the speed of visuals may start to negatively affect the learners, the problem with addressing this issue is that the tipping point may vary among learners based on learner preferences and types of visual content being delivered (Wildemuth et al., 2003). The speed at which auditory media are delivered also plays a role in the cognitive processing of online learners (Mayer, 2014; Mayer \& Moreno, 2003). Perhaps the most commonly researched form of auditory media 
delivery is instructor speech (Guo, Kim, \& Rubin, 2014; Koumi, 2013; Song \& Marchionini, 2007). The appropriate pace of instructor speech is important to ensure that learners effectively process information disseminated to them. Ultimately, speaking rates affect engagement and learning (Guo et al., 2014). Speech delivered quickly may overload learners, while speech that is too slow can fail to stimulate them (Koumi, 2013). There is no agreed upon ideal speed of speech delivery, as existing research varies on what is appropriate. For example, Pastore (2012) suggests a speaking rate of 219 words per minute, while Guo et al. (2014) found that 254 words per minute is more effective in engaging the learners. Additionally, it is important to remember that what may be too fast for one learner may not be so for another (Koumi, 2013).

\section{Intelligibility}

In terms of delivering content through both visual and auditory media, intelligibility refers to the ability of the learner to be able to accurately see or hear content delivered by media in order to make sense of the information (Heribanova, Polec, Ondrušová, \& Hostovecký, 2011). The size of visual media can affect the way in which learners make sense of the information and ultimately engage in the lecture (Molnar, 2017). Size issues with text include cases where font size is too small, rendering the text delivered in instructional situations illegible, negatively affecting comprehension levels (Amigud, Arnedo-Moreno, Daradoumis, \& Guerrero-Roldan, 2017; Sanchez \& Goolsbee, 2010). Concerns among e-learning students pertaining to video or image size include the desire for bigger screens within the lesson because viewing the images on the screen may become difficult to sustain, negatively affecting their learning experience (Al Ghamdi et al., 2016; Kim \& Kim, 2012; Molnar, 2017). Audio issues involving intelligibility occur when students cannot recognize what is being said due to the level of the sound, the mechanical nature of the speech, or technical issues that make the sound distorted (Cunningham, Fägersten, \& Holmsten, 2010; Song \& Marchionini, 2007). When audio is unintelligible, studies have found that it can disrupt the learning process, causing students to go back and replay the audio (Cunningham et al., 2010).

\section{Quality}

Quality of media within video lectures represents the appearance of the presentation and design of the video lecture, or essentially how the learner sees it (Heribanova et al., 2011). It is important to ensure that the quality of visual media is complementary to student engagement and ultimately learning. Leacock and Nesbi (2007) state that esthetics, production values, and overall design all influence the learning process. Visual clarity of the videos has been a cause of concern among e-learning students, which may have a negative effect on how students perceive and ultimately comprehend instruction (Molnar, 2017). One issue among university students is their disdain for outdated videos, negatively affecting their engagement (Curry et al., n.d.). Engagement within e-learning is imperative for the learning process, as it has been specifically linked to learning (Guo et al., 2014). Overall, it has been shown that the delivery of poor-quality visual media has more of a negative effect on the learning process compared to the delivery of high-quality visual media (Leacock \& Nesbi, 2007; Molnar, 2017). 


\section{Media diversity}

Media diversity in terms of video lectures represents the use of a variety of types of media to deliver information to the learners throughout the lesson (Costley \& Lange 2017a). Issues may occur among learners online when there is a lack of media diversity. The presentation of content through diverse forms of media plays a significant role in the way students process information (Costley \& Lange 2017a; Hughes et al., 2018; Hughes et al., 2019a). Based on Paivio's (1991), dual coding theory commonly referenced in instructional media research (Kirschner, Park, Malone, \& Jarodzka, 2017; Mayer \& Moreno, 2003; Pastore, 2012; Ramlatchan, 2019), Mayer (2014) explains that when diverse forms of media are delivered, online learners can process the information through dual coding that takes place through both verbal and nonverbal cognitive channels. The verbal channel processes media such as text and speech, while the nonverbal channel processes media such as graphics and animation (Paivio, 1991). When a combination of various forms of media is displayed concurrently, these two channels work together to make better sense of the information (Schmidt-Weigand \& Scheiter, 2011). Additionally, using both auditory and visual media to deliver instruction further aids learners in making connections between separate bits of information (Mayer, 2014). So the problem is not media diversity itself but rather a lack of media diversity that can limit the information processing potential of online learners. This is supported by Costley and Lange's (2017a) study that showed students who lacked media diversity were disadvantaged in regards to understanding the content delivered to them.

\section{Congruence}

Congruence within video lectures represents a connection between multiple pieces of information presented through various media sources (Brante \& Holmqvist, 2017). Therefore, a lack of congruence occurs when learners have difficulty making sense of multiple media sources used at the same time (Brante \& Holmqvist, 2017). When instructors use diverse forms of media, they need to make sure the various forms of media complement each other rather than distract the learners. Extraneous processing that negatively affects learning occurs when learners become distracted by trying to make sense of two or more unrelated forms of media simultaneously (Lange \& Costley 2019; Leppink, Paas, Van der Vleuten, Van Gog, \& Van Merriënboer, 2013). Additionally, physically separating complementary sources of information from each other on the screen can create additional distractions that negatively affect information transfer (Chen \& Wu, 2015; Kizilcec et al., 2015; Mayer, 2014).

\section{Methods}

Study context

This study focuses on student perceptions of video lectures at the Open Cyber University (OCU) in South Korea. The OCU provides online credit courses for students from an association of traditional brick-and-mortar universities (Jung \& Rha, 2001). In order to get a sense of how students engage in the content, the authors of this study examined a random sample of 10 OCU video lectures from a variety of disciplines. Each weekly video lecture for the courses lasts anywhere from 20 to $30 \mathrm{~min}$ in length, and 
consists of a talking head (professor) who delivers verbal, textual, and graphical content associated with the course. During the lectures, the students can make use of various learner control options including selecting supplementary links, downloading lesson summaries, taking online quizzes to assess their progress, bookmarking specific portions of the video lecture, skipping segments of the lecture, selecting a specific part of the lecture to view, choosing the speed at which they want to watch the lecture, and re-watching any portion of the lecture they wish.

\section{Procedures and overview of data}

As part of a larger project examining issues within online learning among university students in South Korea, the participants in this study initially answered survey questions regarding their experiences taking online courses in the OCU. The items for the survey were first translated from English to Korean by an expert in online learning and the OCU. Following that, the survey was put into a Google Sheets form and sent to the OCU ethics and administration center. After the OCU had checked its contents and determined it to be appropriate for their students, the survey was posted on the main administrative board of the OCU.

At the conclusion of the survey, participants were given an option to provide openended comments about their experience using the OCU. A total of 1784 participants took part in the initial survey. Of the entire study population, $57 \%$ were female and $43 \%$ were male. The average age was 23.6 , with a standard deviation of 4.3. Of those 1784 survey participants, a total of 654 of them (37\%) also provided open-ended comments about their experience with the OCU at the end of the survey. The comments were subsequently translated from Korean to English for further analysis. These comments provided by the 654 participants at the conclusion of the survey, rather than the actual survey itself are the main focus of the present study.

As this research was focused on the negative aspects of media, comments that were related to issues other than negative media delivery were not used for further analysis. This left 177 total comments directly related to negative media issues of the OCU. These 177 students are the main focus of this study, as it is their comments that form the basis of the study. Of those 177 participants, $59 \%$ were female and $41 \%$ male. The average age was 24.5 with a standard deviation of 6.5. Within some of the comments made by these participants, there were multiple complaints related to varying issues. There were 211 total complaints regarding the use of media in the OCU made by the 177 participants, meaning that some participants (17) made complaints related to multiple categories, while most (160) made complaints regarding only one category. The authors read through the comments and arranged them into the same five corresponding categories previously identified in the examination of existing online learning media research: pace, quality, intelligibility, media diversity, and congruence. These complaints form the basis of the analysis of the current study in an attempt to identify the similarities of the complaints with what was looked at in the review of online learning research, to examine the pedagogical ramifications, and to suggest specific recommendations to address the media-related issues.

The categories for the various media factors were derived from existing research. The justification for labeling the factors as we did and for categorizing the participants into specific media factors is provided below, along with common complaint types for each category. 
Pace of content delivery through instructional media is defined by Fisher et al. (2017) as the speed and the tempo of which media content is delivered. Within Fisher et al.'s (2017) research along with all other media pace research cited in the current study, we identified various keywords that refer to the pace of media content delivery, along with various types of instructional media. These words include speed, fast, faster, slow, slower, quick, quickly, rate, and time. Therefore, when selecting participant complaints associated with the pace of media content delivery, these same keywords in addition to words associated with these keywords were used in the selection for analysis. Common complaints regarding pace in this study are listed below:

I have to watch the video lecture again because the class progresses faster than the previous course I took. It is inconvenient to click or to turn back.

My professor is so slow that I always keep the speed at 2.0

Intelligibility of media-based content delivery is defined by Heribanova et al. (2011) as the ability of the learner to be able to accurately see or hear content delivered by media in order to make sense of the information. Keywords found in the literature regarding media intelligibility studies referenced in the current study include size, big, bigger, small, smaller, low, high, and distorted. In the context of the examined research, these words were all associated with aspects of both audio and visual media that negatively affect how learners can either see or hear the content. Therefore, when selecting participant complaints associated with the intelligibility of media content delivery, these same keywords in addition to words associated with the keywords were used in the selection for analysis. Common complaints regarding intelligibility in this study are listed below:

It is inconvenient to view the lecture because the video is too small even in full screen.

It is inconvenient because the size of the text in the lecture is too small.

The voice of the professor is low (even if the volume is maximized).

There is a phenomenon that the professor's voice is ringing (echoing?).

Quality of media-based content delivery is differentiated from intelligibility by Heribanova et al. (2011) in that it refers to the way in which learners see or hear it in order to stay engaged, rather than the level of accuracy the learners can see or hear it. Heribanova et al. (2011) emphasize that poor quality of visuals and audio does not preclude learners from accurately recognizing the content but rather causes them to become more disengaged in it. All media quality research cited in the current study referenced quality in a way where it negatively affects student learning by causing a lack of interest, lack of motivation, lack of engagement, etc. rather than the inability to see or hear the content accurately. Common quality keywords used in the research include good, bad, poor, new, old, outdated, clarity, clear, and unclear. Therefore, these keywords or words associated with these keywords were identified within the participant complaints, 
and those complaints were used for analysis. Some common student complaints used for quality are listed below.

Compared to other cyber lectures, the OCU seems to have poor video quality.

Image quality and color are too bad.

I will not participate next semester. The video lecture is old.

Media diversity has been defined as the use of a variety of types of media to deliver information to the learners throughout the lesson (Costley \& Lange 2017a). All media diversity research referenced in the current study refer to studies conducted involving multiple types of media within video lectures. Therefore, student comments that were reflective of complaints about a lack of varied media sources were categorized into media diversity issues and used for analysis. Common media diversity complaints made by the participants of this study are listed below.

Oh, why did you give a lecture with you just sitting down and reading?

In some lectures, the topic is only presented verbally, which makes it difficult to understand. I hope that all the lectures will provide video and voice at the same time.

Congruence of media-based content has been defined as a connection made between multiple pieces of information presented through various media sources (Brante \& Holmqvist, 2017). All of the congruence research examined in this study focused on the difficulty learners have making connections between multiple sources used at the same time. Therefore, all student complaints that were reflective of this issue were categorized as congruence. Some common congruence complaints made by participants of this study are listed below.

The voice in the lecture that I have to listen to is mixed with other noises so I cannot concentrate and listen to it.

When a professor puts handwriting on a video, it will be out of sync after a few seconds.

"I would like to see a little more lecture information at a glance without scrolling."

\section{Results}

Q1: Regarding the first research question pertaining to the extent of media issues identified by the participants in our study, Table 1 shows the amount of participants who complained about media issues, and Table 2 quantifies the type of complaints by detailing the number and percentage of complaints in-line with categories identified through a review of existing research. 
Table 1 Results: media delivery complaints quantified at the level of participants $(n=654)$

\begin{tabular}{lll}
\hline Category & Quantity & Percentage \\
\hline Made one or more complaints about media delivery & 177 & $27 \%$ \\
Made one or more comments not related to media complaints & 477 & $73 \%$ \\
\hline
\end{tabular}

Out of the 654 students who commented about their experiences with the OCU, a total of 177 (27\%) made one or more negative complaints about media delivery, while 477 (73\%) reported no issues related to media delivery.

Of the 211 total complaints made by the 177 participants, 72 (34\%) were about quality, 49 (23\%) were about intelligibility, $42(20 \%)$ were about speed, 35 (17\%) were about media diversity, and $13(6 \%)$ were about congruence.

Q2: Regarding the second research question, the underlying pedagogy that explains the negative effect on learning caused by inadequate media delivery identified by participants in this study is detailed in Table 3. The table also includes the media category, explanations of common complaints from the participants, and the source from which the pedagogical theory derives. It should be noted that the pedagogical explanations are explained in more detail in the "Discussion" section of this study.

Q3: Table 4 reveals the recommendation for each type of complaint within all five categories examined in this study. It is also noted where the recommendations derived from, with some of the recommendations based on ideas from existing research and others developed by the researchers of this study. The results are explained in more detail in the "Discussion" section of this study, and the recommendations with no in-text citation represent original contributions by the authors of this study. The discussion that follows will also go into more detail by providing pedagogical justification for the recommendations.

\section{Discussion}

Although there is no shortage of research covering media delivery issues within video lectures, it remains unclear as to the extent of these issues within online university courses. This study provides an account of the number of students from this study who experience common media delivery issues discussed in research, and to what extent they experience each categorized media issue. This gives us a sense of what takes place within this specific study of online university students in South Korea, with $27 \%$ of those who provided comments on their experiences claiming they experienced mediarelated issues. This discussion outlines common issues that may be found in online learning environments. The present study adds to the field of education technology research by looking at media delivery from a broad student-focused perspective.

Table 2 Results: types of media delivery complaints quantified at the level of complaint $(n=211)$

\begin{tabular}{lll}
\hline Category & Quantity & Percentage \\
\hline Quality issues & 72 & $34 \%$ \\
Intelligibility issues & 49 & $23 \%$ \\
Pace issues & 42 & $20 \%$ \\
Diversity issues & 35 & $17 \%$ \\
Congruence issues & 13 & $6 \%$ \\
\hline
\end{tabular}


Table 3 Results: common complaints and pedagogical implications

\begin{tabular}{|c|c|c|c|}
\hline Category & Common complaint & Theory & Source \\
\hline \multirow[t]{2}{*}{ Pace } & $\begin{array}{l}\text { The information is delivered too } \\
\text { quickly. }\end{array}$ & Limited Capacity Theory & $\begin{array}{l}\text { Mayer and Moreno } \\
(2003)\end{array}$ \\
\hline & $\begin{array}{l}\text { The information is delivered too } \\
\text { slowly. }\end{array}$ & Reversal effect & Koumi (2013) \\
\hline \multirow[t]{4}{*}{ Intelligibility } & The video is too small. & \multirow[t]{4}{*}{ Extraneous Processing } & \multirow{4}{*}{$\begin{array}{l}\text { Leppink et al. (2013) } \\
\text { Cierniak et al. (2009) }\end{array}$} \\
\hline & The text is too small. & & \\
\hline & $\begin{array}{l}\text { The voice of the instructor is too } \\
\text { low. }\end{array}$ & & \\
\hline & The instructor's voice is distorted. & & \\
\hline \multirow[t]{3}{*}{ Quality } & There is poor video quality. & \multirow{2}{*}{$\begin{array}{l}\text { Concentration, interest, and attention } \\
\text { reduction }\end{array}$} & \multirow[t]{2}{*}{ Molnar (2017) } \\
\hline & There is poor image quality. & & \\
\hline & The video lecture is outdated. & Engagement reduction & Curry et al. (n.d.) \\
\hline $\begin{array}{l}\text { Media } \\
\text { diversity }\end{array}$ & $\begin{array}{l}\text { The video lecture lacks media } \\
\text { diversity. }\end{array}$ & Generative Theory & Mayer (2014) \\
\hline \multirow[t]{3}{*}{ Congruence } & $\begin{array}{l}\text { The video lecture contains } \\
\text { extraneous noise. }\end{array}$ & \multirow[t]{3}{*}{ Extraneous processing } & \multirow[t]{3}{*}{$\begin{array}{l}\text { Leppink et al. (2013) } \\
\text { Cierniak et al. (2009) }\end{array}$} \\
\hline & $\begin{array}{l}\text { The video lecture requires split- } \\
\text { attention. }\end{array}$ & & \\
\hline & Media sources are out of sync. & & \\
\hline
\end{tabular}

Table 4 Results: common complaints and recommendations

\begin{tabular}{|c|c|c|c|}
\hline Category & Complaint & Recommendation & Source \\
\hline \multirow[t]{4}{*}{ Pace } & \multirow[t]{2}{*}{ Too fast } & Segmentation & Mayer (2014) \\
\hline & & Modified segmentation & Self-developed \\
\hline & \multirow[t]{2}{*}{ Too slow } & User incremental speed controls & Wildemuth et al. (2003) \\
\hline & & Multiple version production & Self-developed \\
\hline \multirow[t]{5}{*}{ Intelligibility } & \multirow[t]{2}{*}{ Video too small } & User control zoom feature & $\begin{array}{l}\text { Maniar, Bennett, Hand, \& Allan } \\
\text { (2008) }\end{array}$ \\
\hline & & Extraneous image/text removal & Self-developed \\
\hline & Text too small & User control of font size & Amigud et al., (2017) \\
\hline & Voice too low & $\begin{array}{l}\text { User control option to increase only } \\
\text { speaker's voice }\end{array}$ & Self-developed \\
\hline & Voice distorted & Subtitle option for compensation & Cunningham et al. (2010) \\
\hline \multirow[t]{2}{*}{ Quality } & Poor video/quality & $\begin{array}{l}\text { Use videos produced with higher } \\
\text { resolution }\end{array}$ & $\begin{array}{l}\text { Molnar, El-Haddadeh, \& Hackney } \\
\text { (2013) }\end{array}$ \\
\hline & Outdated video & $\begin{array}{l}\text { Formative assessments to alleviate } \\
\text { distractions }\end{array}$ & $\begin{array}{l}\text { Perko, Chaney, Chaney, Gordon, \& } \\
\text { Eddy (2008) }\end{array}$ \\
\hline $\begin{array}{l}\text { Media } \\
\text { Diversity }\end{array}$ & $\begin{array}{l}\text { Lacks media } \\
\text { variety }\end{array}$ & Link audio and visuals together & $\begin{array}{l}\text { Schmidt-Weigand \& Scheiter } \\
\text { (2011) }\end{array}$ \\
\hline \multirow[t]{3}{*}{ Congruence } & Extraneous noise & $\begin{array}{l}\text { Volume control options to mute only } \\
\text { background noise }\end{array}$ & Self-developed \\
\hline & Split-attention & $\begin{array}{l}\text { Media sources placed in close proximity } \\
\text { to each other }\end{array}$ & $\begin{array}{l}\text { Mayer \& Moreno (2003) } \\
\text { Mayer (2014) }\end{array}$ \\
\hline & $\begin{array}{l}\text { Media sources out } \\
\text { of sync }\end{array}$ & Summative assessments & Self-developed \\
\hline
\end{tabular}


Furthermore, solutions with theoretical justifications are provided to help improve teaching and learning in situations where instruction media is used online.

\section{Quality and intelligibility}

Among all of the complaints, quality issues were of the utmost concern (34\%) followed by intelligibility $(23 \%)$, pace $(20 \%)$, media diversity $(17 \%)$, and congruence $(6 \%)$ issues in that order. Although no specific data was found in existing research that showed what percentage of online learning perceive quality issues as a problem, it does make sense that this would be a major category of concern due to the fact that the quality of video lectures is of critical importance when it comes to engaging with them (Molnar, 2017; Molnar et al., 2013). Because the quality of media used in video lectures is a noticeable factor during literally every moment of the lesson, a case can be made that it is what they perceive first and foremost, and therefore problems with it may be more abundant than other factors. That makes it all the more critical for e-learning instructors to deliver content through the use of good quality media. The same can be said about intelligibility, which received the second highest number of complaints. At every moment of the video lecture, the content is either intelligible or not, and the fact that within the sample of this study, participants found this to be a significant issue should bring attention to potential solutions to intelligible media problems.

\section{Pace}

Like quality and intelligibility, research has not been found regarding the amount of online learners who have issues with the pace of the content delivered through instructional media. However, the fact that $20 \%$ of the complaints were categorized as pace may be reflective of the fact that other research has shown that the pace of mediabased content delivery is one of the top priorities among online learners (Kwon, Saparova, \& Hoffman, 2015). Because of this reason, students may be sensitive to issues involving pace due to the importance they place on it in regard to their learning.

\section{Media diversity and congruence}

Regarding the relatively few complaints about issues with media diversity, this may be due to the increasing usage of multiple media sources throughout an average video lecture (Costley \& Lange 2017b), therefore leaving little room for complaints regarding a lack of media diversity. The relatively low amount of congruence complaints was therefore all the more surprising because the more diverse media there is the more problems one would expect to see in the connection between the diverse media. It could be that students may not even realize that multiple sources are actually complicating their cognitive processing if it is actually happening. This would be an interesting direction to take for future research.

\section{Overview of pedagogical implications}

In the discussion that follows, we look at specific comments raised by participants of this study that represent common complaints within the five media categories. We not only discuss how students perceive issues with media delivery in online university courses but also discuss pedagogical implications and recommend ways to improve 
video lectures through effective use of media. This is an important issue within elearning because extant research shows that although media use in video lectures has its upside, learning can be negatively affected if used in ways that do not promote learning. The following suggestions are a combination of ideas generated from analysis of existing research in addition to ideas developed by the authors of this study. Ultimately, these recommendations should provide a better learning experience for students participating in online university courses.

\section{Speed of materials and learning theories}

Media being displayed too quickly can complicate learning processes (Mayer, 2014; Mayer \& Moreno, 2003; Wildemuth et al., 2003). Learning from fast-paced media can be complex, as students fail to obtain critical information, often times due to the inability to recognize graphical images and comprehend text because of it (Wildemuth et al., 2003). The lack of comprehension when media are displayed at high rates can be explained through the limited capacity theory, which states the working memory contains a limited capacity to organize and process modality-specific information and therefore cognitive overload can occur when too much information is presented at a high rate of speed (Mayer, 2014). This can create extraneous processing if students are required to go back and process information that they missed the first time around because it was delivered too fast (Mayer, 2014). While media delivered at too high of a rate can create cognitive processing issues, media that are too slow may cause what is known as a reversal effect. This occurs when learners are capable of understanding the material, but their learning is negatively affected as they become disengaged due to the slow delivery (Koumi, 2013). This is particularly the case when instructor speech is perceived by students as delivering verbal information at too slow of a rate (Koumi, 2013).

\section{Instructional segmentation}

The use of video segmentation is recommended for dealing with either auditory or visual media being delivered too fast. Segmentation allows learners to watch a video lecture separated into predetermined segments (Mayer \& Moreno, 2003). It essentially acts as a mechanism to slow down the pace of verbal and auditory media, which reduces cognitive load by giving students a series of breaks to process information before moving on to subsequent segments (Fisher et al., 2017; Mayer \& Moreno, 2003). A study performed by Doolittle, Bryant, \& Chittum (2015) showed that students who received a video lecture separated into 28 manageable segments performed better than students who received a lecture containing the same information but with a significantly reduced number of segments. Although segmentation appears to help reduce cognitive load, it is important to remember that not everybody processes information at the same rate. Information that is segmented into a specific number of segments may be necessary for cognitive load reduction for one student but can create disinterest by another due to an unwanted slower pace (Koumi, 2013). A solution to this issue may be to give even more control over how online learners receive the information. Rather than presenting the content into 16 predetermined segments, for example, the students can be given the option of selecting how many segments they feel they need based on their prior knowledge of the content. This would limit the information 
needed to manage in each segment for those who need more processing time and allow those who are able to process information at a higher rate to manage longer segments containing more information to be processed before moving on to the next segment.

\section{Incremental speed controls}

In response to students becoming disinterested in the content from media delivered at a slow rate, Wildemuth et al. (2003) suggest various levels of speed increments so students can adjust the speed at which the video is presented based on their needs. Their claim is that this user control option is useful because it allows the learner to increase the speed of the media if the content is perceived as easily manageable. This is based on their findings that while a specific speed may be needed for some content that same speed may not be appropriate for other content, as learning at a particular speed varies based on the content. One limitation of their study, however, is that it was conducted on only visual aspects of the video, not auditory aspects. Slowing down the speed of a video containing audio narration creates a problem for users in that it distorts the audio, which contributes to processing issues among the learners due to the cognitive strain placed on trying to understand the distorted audio (Cunningham et al., 2010). A solution to this problem would be to produce multiple versions with the instructor speaking naturally at a different rate per version. The user can then select the video with a specific speed of the instructor's voice based on their own learning needs, which would in theory avoid any extraneous processing that would take place when trying to decipher distorted speech created by slowing down the speed of one pre-recorded video.

\section{Intelligibility issues and solutions}

Small visuals on a screen can negatively affect the desire for learners to put forth the effort to learn, as limited visual perception of small images and text ultimately has a negative effect on one's attention span (Molnar, 2017). Additionally, small visuals can create extraneous cognitive processing by exerting additional effort to make sense of undersized images or text, which ultimately negatively affecting content comprehension (Mayer, 2014; Maniar et al., 2008). Auditory intelligibility issues run the risk of students not being able to recognize what is being said, which has been shown to cause a decrease in comprehension levels (Pilarski, Alan Johnstone, Pettepher, \& Osheroff, 2008). Cunningham et al. (2010) report that when technical issues arise, students tend to rely on accompanying text, but if there is no accompanying text, students are left with no other option but to miss potentially crucial information.

When intelligibility issues arise, user control options can allow students to adjust size as needed. Doing so should address issues raised by unintelligible visuals such as cognitive load and attention problems (Maniar et al., 2008; Shudong, Higgins, \& Shima, 2005). Because the preferred size of the text may vary based on the learner, students should be able to choose font size based on preference. This is made possible through user interfaces which assist learners by allowing them to control font size of e-learning presentations (Amigud et al., 2017) There are times where it may not be feasible to fill the entire screen with an embedded video because other portions of the screen may be needed to show additional content through other forms of media such as text, images, or a talking head. This may create issues with students' perceptions of video size. When 
visuals in online video lectures create sustainability issues due to lack of size, user control options such as a zoom feature can be added (Maniar et al., 2008). However, this may affect cognitive processing because zooming in too much on one aspect of the video eliminates peripheral features in the video, causing students to rely on their memory to integrate the removed parts of the video to the parts being zoomed in on (Maniar et al., 2008). In this case, Maniar et al. (2008) recommend using simple animations rather than video clips to convey a point if possible. This is because they are a more direct representation of objects compared to more elaborate images and videos that can include distracting and extraneous content that does not contribute to learning (Maniar et al., 2008). However, there may be times when actual video is needed in order to portray essential detail that an animation may lack. In such cases, it would make sense to digitally remove any extraneous text or images in the video in order to prevent excessive extraneous processing.

\section{Audio intelligibility issues and solutions}

Regarding audio intelligibility, students in this study complained that they could not hear the professor, even if the sound was turned up. Issues like this can take place when there is only one volume control for the entire sound of the presentation, which includes not only the professor's voice, but also background noise and music. A solution to such an issue may be to design a learner control option that allows students to control only the volume level of the person who is speaking. This would allow learners to focus on the important aspects of the lecture, while tuning out extraneous sound, resulting in lower levels of cognitive load (Mayer \& Moreno, 2003). If technical issues disrupt the sound delivery, instructors should use accompanying text for compensation (Cunningham et al., 2010). Perhaps, this can be done by allowing learners to click on subtitles or some other mechanism that allows text to accompany the narration. An option to either include subtitles or not would be useful based on whether the text is actually needed or not. If the sound delivery is not disrupted, leaving the subtitles in place can create extraneous processing, as learners are faced with processing redundant information from multiple media sources (Mayer, 2014). Therefore, giving them the option of turning the subtitles on only when needed for situations such as sound distortion would avoid any unnecessary cognitive processing.

\section{Visual quality issues and solutions}

When poor visual media are delivered, students' understanding of the content can be negatively affected (Molnar, 2017). Additionally, decrease in concentration due to poor quality video lectures is reflective of the fact that poor visual media quality decreases interest and attention (Molnar et al., 2013). Furthermore, visual media that are not clearly displayed is a critical design flaw, as research has found that students learn better from clear video lectures with higher resolution compared to less clear ones (Molnar, 2017; Molnar et al., 2013). Finally, the use of old videos is problematic for students, as outdated videos have been shown to have a negative effect on engagement which leads to lower levels of learning (Curry et al. n.d.).

Quality concerns found in this study are supported by research that states that poor visual quality of video lectures ultimately decreases attention and levels of understanding among online learners (Molnar, 2017). Instructors need to make sure that the images and videos presented within online lectures are as clear as possible before using 
them to deliver information. The specific levels of brightness, speed, and number of pixels to be used should ensure the video lecture maintains students' attention. This is in line with research conducted by Molnar et al. (2013) who found that students had a better learning experience from videos that were clearer due to higher resolution. Existing research has also addressed issues regarding outdated videos. Acknowledging that fashion and styles change over the years, Perko et al. (2008) recommend formative assessments of the videos to make sure they have a contemporary feel to them, which should alleviate distractions from learning.

\section{Increase the amount of media diversity}

Students commenting on the lack of media diversity is concerning, as it has been shown in a general sense that the more media diversity used by online instructors, the better students learn (Costley \& Lange 2017a, 2017b; Kim et al., 2011). Various forms of media should be used to complement each other in a way that promotes learning in an online environment. Reflective of this notion, the Generative Theory of multimedia learning states that more cognitive connections can be made through the use of both audio and visual media at the same time (Mayer, 2014). Additionally, it has been found that when audio is linked to video, students make sense of the information better than if audio is used alone (Schmidt-Weigand \& Scheiter, 2011). Media diversity has been proven to aid the learning process and keep students engaged in the lesson (Costley \& Lange 2017a, 2017b; Kim et al., 2011). Rather than providing audio or visuals alone, linking both audio and visuals to complement each other makes for a better learning experience (SchmidtWeigand \& Scheiter, 2011).

\section{Congruence issues and solutions}

When using media diversity within video lectures, care needs to be taken to avoid issues with congruence. A common complaint with congruence is when distracting background noise occurs; it becomes more difficult to concentrate on the lecture. This is a problem because adding extraneous sound effects and background noise to a lecture may create unnecessary cognitive processing, which negatively affects learning (Mayer, 2014). Another common issue involving congruence is when different forms of media do not properly sync up with each other. This becomes a problem for learning because extraneous processing occurs when learners attempt to store content delivered by speech in their working memory while at the same time process written text that is lagging behind the speech (Lange \& Costley 2019; Leppink et al., 2013). Another common theme regarding media congruence is when students have to split their attention between sources, holding one bit of information from one part of the screen in short term memory and scrolling up to another part of the screen to connect it to another piece of information, for example. Splitting one's attention between sources in this fashion ultimately distracts learners and diverts cognitive processing to information that does not contribute to learning (Mayer, 2014).

When background noise is distracting the learner from hearing what the instructor is saying, it would be beneficial to provide volume control options that give students the ability to mute background noise if necessary. This differs from traditional sound controls in video lectures in that it allows learners to control the sound of a particular aspect of the lecture rather than the overall sound of 
the presentation. This will prevent distractions and allow students to focus their cognitive processing on more necessary information being delivered to them by the instructor. It is also imperative that instructors make sure that text is in sync with associated audio. Technical issues such as these need to be avoided. Perhaps summative assessments throughout the semester can ensure that issues such as these do not come into play. Preventing issues with synchronization will ultimately prevent learners from wasting cognitive effort on processes that distract them from the learning process. To avoid issues with the split-attention effect, online instructors should place complementary media sources in close proximity to each other (Mayer, 2014). Doing so would alleviate the need to hold bits of information from one source in the working memory while attempting to locate the accompanying source. If both sources are in close proximity to each other, students are more likely to hold the information from source A before connecting it to source B.

\section{Conclusion}

These results are particularly useful due to the increased accessibility of e-learning for learners in South Korea and around the world, as well as the fact that video lectures are specifically designed to meet the learning needs of a wide range of learners with varying characteristics (Alraimi et al., 2015; Breslow et al., 2013; Kim et al., 2011). Providing an account of the extent of various media delivery issues in addition to various online learner experiences with media delivery allows researchers to get a clearer picture of issues that university students face when participating in video lectures. This study not only points out these issues, but also provides solutions and beneficial guidelines for instructors who want to improve the e-learning experience of their students. With the wealth of information available from the use of various visual and auditory media, instructors should not back away from using them but should be aware that ineffective media delivery could lead to issues involving learning. This study provides useful information about media delivery within video lectures, but it does not come without limitations. Although we get a good sense of the extent of these issues within our study of online university learners in Korea, by no means does this definitively represent the online learning community as a whole. Multiple studies with much larger sample sizes would provide a better sense of the extent of media issues occurring within video lectures. Additionally, controlled experiments can complement these findings by showing precisely what occurs within e-learning environments when media are used in a variety of different ways. It is recommended that this study should serve as a starting point to further research involving various types of media within e-learning environments. Finally, future research should also focus on positive responses about media delivery in e-learning environments, which would add to the recommendations of the current study.

\section{Acknowledgements}

The authors would like to acknowledge Dr. Seunglock Han for his help in securing the OCU's permission to conduct this research.

\section{Authors' contributions}

$\mathrm{CL}$ was responsible for writing the majority of the text found in the paper in addition to contributing to the methodological design and organization of data. JC was responsible for the initial design and conceptualization of the paper, as well as writing some sections and organization of data. The authors read and approved the final manuscript. 
Availability of data and materials

As per the rules of the OCU, the data for this study cannot be made publicly, though it is available for the reviewers on request.

\section{Ethics approval and consent to participate}

Participants gave written consent for their responses to be used for research. This research was approved by the governing ethical body (Hangjeongshil) of the OCU, which checks and approves all research done at the OCU.

\section{Competing interests}

The authors declare that they have no competing interests.

\section{Author details}

${ }^{1}$ Department of British and American Humanities, Dankook University, Yongin, South Korea. ${ }^{2}$ Educational Research Lab, Prince Sultan University, Prince Nasser Bin Farhan St, Riyadh 12435, Saudi Arabia.

Received: 3 October 2019 Accepted: 19 February 2020

1.

\section{References}

Al Ghamdi, E., Yunus, F., Da'Ar, O., El-Metwally, A., Khalifa, M., Aldossari, B., \& Househ, M. (2016). The effect of screen size on mobile phone user comprehension of health information and application structure: An experimental approach. Journal of Medical Systems, $40(1), 11$.

Alraimi, K. M., Zo, H., \& Ciganek, A. P. (2015). Understanding the MOOCs continuance: The role of openness and reputation. Computers \& Education, 80, 28-38.

Amigud, A., Arnedo-Moreno, J., Daradoumis, T., \& Guerrero-Roldan, A. E. (2017). Using learning analytics for preserving academic integrity. The International Review of Research in Open and Distributed Learning, 18(5), 192-210.

Brante, E. W., \& Holmqvist, M. (2017). Reading from multimedia materials: Benefits of non-congruent pictures on reading comprehension for dyslexic readers. The Turkish Online Journal of Educational Technology-TOJET, 16(1), 101-114.

Breslow, L., Pritchard, D. E., DeBoer, J., Stump, G. S., Ho, A. D., \& Seaton, D. T. (2013). Studying learning in the worldwide classroom research into edX's first MOOC. Research \& Practice in Assessment, 8, 13-25.

Chen, C. M., \& Wu, C. H. (2015). Effects of different video lecture types on sustained attention, emotion, cognitive load, and learning performance. Computers \& Education, 80, 108-121.

Cierniak, G., Scheiter, K., \& Gerjets, P. (2009). Explaining the split-attention effect: Is the reduction of extraneous cognitive load accompanied by an increase in germane cognitive load? Computers in Human Behavior, 25(2), 315-324.

Costley, J., \& Lange, C. H. (2017a). The effects of lecture diversity on germane load. International Review of Research in Open and Distributed Learning, 18(2), 27-46.

Costley, J., \& Lange, C. H. (2017b). Video lectures in e-learning: Effects of viewership and media diversity on learning, satisfaction, engagement, interest, and future behavioral intention. Interactive Technology and Smart Education, 14(1), 14-30.

Cunningham, U. M., Fägersten, K. B., \& Holmsten, E. (2010). "Can you hear me, Hanoi?" Compensatory mechanisms employed in synchronous net-based English language learning. The International Review of Research in Open and Distributed Learning, 11(1), 161-177.

Curry, C., Bernard, A., \& Kolek, T. (n.d.). IQP: An investigation on the effect of interactive multimedia video on student engagement and learning. Retrieved from http://web.wpi.edu/Pubs/E-project/Available/E-project-052311-192512/unrestricted/IQP-_An_ Investigation_on_the_Effect_of_Interactive_Multimedia_Video_on_Student_Engagement_and_Learning.pdf

Doolittle, P. E., Bryant, L. H., \& Chittum, J. R. (2015). Effects of degree of segmentation and learner disposition on multimedia learning. British Journal of Educational Technology, 46(6), 1333-1343.

Fisher, S., Howardson, G., Wasserman, M. E., \& Orvis, K. (2017). How do learners interact with e-learning? Examining patterns of learner control behaviors. AIS Transactions on Human-Computer Interaction, 9(2), 75-98.

Guo, P. J., Kim, J., \& Rubin, R. (2014). How video production affects student engagement: an empirical study of MOOC videos. In Proceedings of the First ACM Conference on Learning @ Scale Conference, (pp. 41-50). New York: ACM.

Heribanova, P., Polec, J., Ondrušová, S., \& Hostovecký, M. (2011). Intelligibility of cued speech in video. World Academy of Science, Engineering and Technology, 79, 492-496.

Hughes, C., Costley, J., \& Lange, C. (2018). The effects of self-regulated learning and cognitive load on beginning to watch and completing video lectures at a cyber-university. Interactive Technology and Smart Education, 15(3), 220-237.

Hughes, C., Costley, J., \& Lange, C. (2019). The effects of multimedia video lectures on extraneous load. Distance Education, $40(1), 54-75$.

Jung, I., \& Rha, I. (2001). A virtual university trial project:Its impact on higher education in South Korea. Innovations in Education and Teaching International, 38(1), 31-41.

Kim, D., \& Kim, D. J. (2012). Effect of screen size on multimedia vocabulary learning. British Journal of Educational Technology, $43(1), 62-70$

Kim, J., Kwon, Y., \& Cho, D. (2011). Investigating factors that influence social presence and learning outcomes in distance higher education. Computers \& Education, 57(2), 1512-1520.

Kirschner, P. A., Park, B., Malone, S., \& Jarodzka, H. (2017). Toward a cognitive theory of multimedia assessment (CTMMA). In Learning, design, and technology: An international compendium of theory, research, practice, and policy, (pp. 1-23). Cham: Springer.

Kizilcec, R. F., Bailenson, J. N., \& Gomez, C. J. (2015). The instructor's face in video instruction: Evidence from two large-scale field studies. Journal of Educational Psychology, 107(3), 724-740.

Koumi, J. (2013). Pedagogic design guidelines for multimedia materials: a call for collaboration between practitioners and researchers. Journal of Visual Literacy, 32(2), 85-114.

Kwon, K., Saparova, D., \& Hoffman, K. (2015). Online lecture capturing system: Expected and actual effects of implementation in a problem-based learning medical curriculum. Medical Teacher, 37(6), 578-584. 
Lange, C., \& Costley, J. (2019). The negative impact of media diversity on self-regulated learning strategies and cognitive load. Issues in Educational Research, 29(1), 158-179.

Leacock, T. L., \& Nesbi, J. C. (2007). A framework for evaluating the quality of multimedia learning resources. Journal of Educational Technology \& Society, 10(2), 44-59.

Leppink, J., Paas, F., Van der Vleuten, C. P., Van Gog, T., \& Van Merriënboer, J. J. (2013). Development of an instrument for measuring different types of cognitive load. Behavior Research Methods, 45(4), 1058-1072.

Maniar, N., Bennett, E., Hand, S., \& Allan, G. (2008). The effect of mobile phone screen size on video based learning. Journal of Software, 3(4), 51-61.

Mayer, R. E. (2014). Multimedia instruction. In Handbook of research on educational communications and technology, (pp. 385-399). New York: Springer.

Mayer, R. E., \& Moreno, R. (2003). Nine ways to reduce cognitive load in multimedia learning. Educational Psychologist, 38(1), 43-52.

Molnar, A. (2017). Content type and perceived multimedia quality in mobile learning. Multimedia Tools and Applications, 76(20), 21613-21627.

Molnar, A., El-Haddadeh, R., \& Hackney, R. (2013). Facilitating the adoption of public services using high definition video: The case of primary education. In Americas conference on information systems. AIS electronic library (AISeL).

Paivio, A. (1991). Dual coding theory: retrospect and current status. Canadian Journal of Psychology/Revue Canadienne de Psychologie, 45(3), 255-287.

Pastore, R. (2012). The effects of time-compressed instruction and redundancy on learning and learners' perceptions of cognitive load. Computers \& Education, 58(1), 641-651. https://doi.org/10.1016/j.compedu.2011.09.018.

Perko, M. A., Chaney, E. H., Chaney, D. J., Gordon, B. C., \& Eddy, J. M. (2008). Lessons lived: Development and discovery in health education distance programs. The Health Education Monograph Series, 25(1), 11-17.

Pilarski, P. P., Alan Johnstone, D., Pettepher, C. C., \& Osheroff, N. (2008). From music to macromolecules: Using rich media/ podcast lecture recordings to enhance the preclinical educational experience. Medical Teacher, 30(6), 630-632.

Ramlatchan, M. (2019). Multimedia learning theory and instructional message design. In M. Ramlatchan (Ed.), Instructional message design: theory, research, and practice, (vol. 1). Norfolk: Kindle Direct Publishing.

Rasch, T., \& Schnotz, W. (2009). Interactive and non-interactive pictures in multimedia learning environments: effects on learning outcomes and learning efficiency. Learning and Instruction, 19(5), 411-422.

Sanchez, C. A., \& Goolsbee, J. Z. (2010). Character size and reading to remember from small displays. Computers \& Education, 55(3), 1056-1062.

Schmidt-Weigand, F., \& Scheiter, K. (2011). The role of spatial descriptions in learning from multimedia. Computers in Human Behavior, 27(1), 22-28.

Shudong, W., Higgins, M., \& Shima, Y. (2005). Teaching English pronunciation for Japanese learners of English online. JALT CALL Journal, 1(1), 39-47.

Sinha, T., Jermann, P., Li, N., \& Dillenbourg, P. (2014). Your click decides your fate: inferring information processing and attrition behavior from mooc video clickstream interactions. arXiv preprint arXiv:1407.7131.

Song, Y., \& Marchionini, G. (2007). Effects of audio and visual surrogates for making sense of digital video. In Proceedings of the SIGCHI Conference on Human Factors in Computing Systems, (pp. 867-876). New York: ACM.

Wildemuth, B. M., Marchionini, G., Yang, M., Geisler, G., Wilkens, T., Hughes, A., \& Gruss, R. (2003). How fast is too fast?: Evaluating fast forward surrogates for digital video. In Proceedings of the 3rd ACM/IEEE-CS Joint Conference on Digital Libraries, (pp. 221-230). Washington, DC: IEEE Computer Society.

\section{Publisher's Note}

Springer Nature remains neutral with regard to jurisdictional claims in published maps and institutional affiliations.

\section{Submit your manuscript to a SpringerOpen ${ }^{\circ}$ journal and benefit from:}

- Convenient online submission

Rigorous peer review

- Open access: articles freely available online

- High visibility within the field

- Retaining the copyright to your article

Submit your next manuscript at $\boldsymbol{\nabla}$ springeropen.com 